\title{
What They Post, Where They Post, and When They Post It: A Content Analysis of Social Media Use of the Top 50 Artists in 2018
}

\author{
Ulf Oesterle \\ Syracuse University \\ This paper was presented at the 2019 International Summit of the \\ Music \& Entertainment Industry Educators Association
}

March 21-23, 2019

\section{https://doi.org/10.25101/19.36}

\section{Abstract}

Social media is an essential tool within the promotional mix for almost every recording artist today. Curating content on multiple social platforms can take many forms ranging from fan interaction and selling product (owned or via brand sponsor), to amplifying traditional press coverage, or could extend to public statements on social issues or political perspectives. These channels can be an extension of the artist's personal voice or can deliver much more curated content managed by an artist team speaking on their behalf. In either case, social media is a direct channel for content distribution. Top artists manage millions of connections across YouTube, Facebook, Instagram, and Twitter alone, while billions of potential fans collectively occupy these platforms. Artists are often encouraged to develop their own brand voice on social media, however examining what others share can provide guidance and direction when establishing a content library and/or a social posting calendar for an artist without one established. This study explores the social channels for the top fifty artists as determined by Billboard in 2018. The content analysis breaks down the mix of content that the official artist social channels share, the frequency of these postings, as well as similarities and differences in usage across platforms over the course of a calendar month. This analysis can be utilized as a guide when developing a strategy for artists looking to establish their own voice on social media.

Keywords: social media, Facebook, Twitter, Instagram, YouTube, content calendar, music industry, artist promotion
Social media is a part of our lives and is often seen as an essential element for brands, celebrities, and musicians. The effective use of social media allows for a direct-to-fan channel and opportunity to connect with followers for personal and promotional purposes. The use of social media can enhance what artists do offline though not all artists effectively use the biggest of platforms. Today we see millions of users on social media on platforms globally. As an artist, or representative of an artist, the use or non-use of each platform should be carefully considered. Understanding how frequently an artist should create content for social media to maintain a position of visibility is important.

Social media has been studied for years in the context of communication. Researchers have looked at the uses and gratifications model (Whiting and Williams 2013) from the social media user perspective and other studies have focused on individual artists and social media use leading up to releases (Morris 2014). Further research by Ronen Shay and Morgan Van Der Horst (2019) studied the use of social media use by brands.

This exploratory study is connected to the artist marketing, fan connection, and brand building in determining a social posting calendar to deliver targeted messages to fans via controlled social channels. How often should artists post content to their social channels? Does a schedule hold true across all platforms or should posting schedules be different across different outlets? To answer these questions, we must first look at what artists are posting now. In determining this, the artists deemed to be at the top of the business ought to be the first artists studied. We could quantify the top artists in a number of ways including by streams, album sales, an artist's concert gross, number of tickets sold, or any number of other measures. Though there will likely be some similarity across these measures, this study uses the 
artists that Billboard presented as the top artists from 2018 as measured by radio airplay, sales data, and streaming data (Billboard 2019).

Social media is seen as an essential element in virtually every current artist promotional strategy and this study focused on the frequency of posts across four major social platforms. The research centered on developing a content calendar for major artists by examining what the Top 50 artists post via their official channels. A consistent message via these channels will keep artists, their work, and celebrity status in front of an audience. The frequency of posts was evaluated over the course of one calendar month, February 2019. This month of twenty-eight days allows for four equal weeks of content to be posted. The Grammy Awards also occur in February so we might anticipate a spike in social activity surrounding this event among the biggest artists in the music business.

The study looked at the top fifty artists of 2018 as determined by Billboard. The selection of the Top 50 was to allow for a potentially larger variety of social media posting strategies among the top artists. Artists studied are indicated by Billboard chart position in Table 1. The top artists are largely male with only twelve female artists represented. There were also only five duos or groups represented.

The data from each artist-owned or official social platform were manually coded, and though this study primarily looks at frequency, additional elements from each post were captured for future analysis. Every tweet, Facebook post, Instagram picture or video, and YouTube video for all fifty artists was analyzed and coded. There were 4,503 total pieces of social media content that satisfied the criteria to be studied. This data set by platform for the month of February 2019 was composed of 2,857 tweets, 800 Instagram posts, 749 Facebook posts, and 97 YouTube videos.

The posts that were studied were designed to be the permanent posts for the artist and not content that expires after a limited time. Instagram or Facebook stories expire after a day and live streams may not be archived. As such, only items posted to pages that were intended to last more than 24 hours were studied.

\section{YouTube}

In the month of February 2019 there were 97 videos uploaded to the official artist accounts. Counted in these 97 are audio streams and/or lyric videos presented on the artist channels. The average number of uploads to YouTube across the sample was 1.97 videos per month or about one video every two weeks. If we drill down slightly deeper we see that 20 of the 50 artists, or $40 \%$, did not post anything to their official artist accounts within the month. There were 14 accounts (28\%) that only posted one time, while 7 accounts (14\%) posted twice per month. This latter
Table 1. Top 50 Artists of 2018 as Ranked by Billboard.

\begin{tabular}{|l|l|}
\hline 1. Drake & 26. Nicki Minaj \\
\hline 2. Post Malone & 27. Demi Lovato \\
\hline 3. Ed Sheeran & 28. Gix9ine \\
\hline 4. Taylor Swift & 29. Chris Stapleton \\
\hline 5.Cardi B & 30. Shawn Mendes \\
\hline 6. XXXTentacion & 31. Florida Georgia Line \\
\hline 7. Imagine Dragons & 32. Lil Baby \\
\hline 8. BTS & 33. Ella Mai \\
\hline 9. Bruno Mars & 34. Bebe Rexha \\
\hline 10. Camila Cabello & 35. G-Eazy \\
\hline 11. Migos & 36. Luke Bryan \\
\hline 12. Travis Scott & 37. YoungBoy Never Broke Again \\
\hline 13. Eminem & 38. Kenny Chesney \\
\hline 14. Ariana Grande & 39. Bazzi \\
\hline 15. Kendrick Lamar & 40. Thomas Rhett \\
\hline 16. Maroon 5 & 41. NF \\
\hline 17. Juice WRLD & 42. Beyoncé \\
\hline 18. Khalid & 43. Lil Wayne \\
\hline 19. Dua Lipa & 44. Lil Pump \\
\hline 20. Halsey & 45. Kane Brown \\
\hline 21. P!nk & 46. Jason Aldean \\
\hline 22. J. Cole & 47. Kanye West \\
\hline 23. The Weeknd & 48. Luke Combs \\
\hline 24. Justin Timberlake & 49. Logic \\
\hline 25. Sam Smith & 50. 21 Savage \\
\hline & \\
\hline
\end{tabular}

figure represents the average for the sample. Four accounts (8\%) posted to YouTube 3 times for the month and there were 5 accounts $(10 \%)$ that posted at least 4 times within the month. The heavy YouTube users for this sample included BTS ( 9 videos) sharing some behind the scenes footage, Ariana Grande (14 videos), and Lil Pump (12 videos) with several audio tracks, and Florida Georgia Line (18 videos) presented a series of videos where they took the viewers behind the song. Maroon 5 posted four videos for the month, 3 of which centered on the road to their Super Bowl performance.

\section{Facebook}

The Facebook activity of the top fifty artists was much higher than that of YouTube. In total, artists and their teams posted 749 times. Some of the posts did include multiple images per post and for the purposes of the study this was counted as one piece of content, thus one post. Of the artists, there were 7 (or 14\%) that did not post for the month. Nearly half (20 artists, $40 \%$ ) posted 4 or fewer times for the month which is an average of one post per week or less. There were heavy Facebook users in the group with Lil Wayne posting 76 times for the month, often posting about 
other artists. Nikki Minaj and Dua Lipa were also heavy Facebook users with over 50 posts per month. Across the sample the artists posted 14.98 times per month or approximately one post every other day.

\section{Instagram}

On Instagram artists posted slightly more than they did on Facebook and collectively posted 800 times across the month. Posts were individual photos, individual videos, or multiple images and videos in one update. The range of posts per day for the entire group was as low as 10 on February 2 and was highest on February 11 when 49 posts took place for the group the day after the Grammy Awards. Overall the artists averaged about 4 posts per week or one post every other day. The group of artists could be further segmented into light users, medium, and heavy users of the platform. There were 15 artists $(30 \%)$ that posted fewer than once per week. Over half of the artists (54\%) posted between once per week and once per day ( 4 to 28 posts per month) and $16 \%$ of the artists posted an average of more than once per day on Instagram.

\section{Twitter}

Twitter is intended to be a platform for shorter messages and exchanges. As such, the use of Twitter based on the number of posts per artist was significantly higher than other platforms. In total the top fifty artists of 2018 tweeted 2,857 times for the month. This is an average of 2.04 tweets per day per artist. Not all artists actively used Twitter and slightly more than one-third (34\%) of the artists posted fewer than 10 tweets for the month. Almost half of the artists (48\%) were moderate Twitter users sending 10 to 100 tweets per month and nine artists (18\%) sent more than 101 tweets per month. One artist account sent 537 tweets for the month.

\section{Conclusion}

In analyzing the heavy social media users studied here, the female pop artists were the heaviest users of social media. Despite the fact that only 12 female artists were represented in the top 50 artists, they represented 8 of the top 10 artists as ranked by tweet volume and six of the top seven artists by number of Instagram posts. Female artists had a very dominant position with a high volume of content being created and distributed across their social channels.

This exploratory study was designed to provide some context when creating a social media content calendar. If we were to take the top fifty artists and focus on their social media use across the four major platforms we would see content calendars that call for posting to YouTube once every two weeks. We'd expect Facebook and Instagram posts to occur about every other day and we'd see an average of two tweets per day.

\section{Future Research}

This study is only a starting point for future research in social media. This study did not delve into every single opportunity these social platforms present to artists. As mentioned, this study focused on posts intended to be permanent and did not study stories and live streams. Artists do use these streams and stories that expire so future research should include their use and would likely need to be completed in real time as opposed to a historical exploration of content. Artist use of Snapchat would also provide an additional platform to examine. Additional research across international social platforms will also provide more breadth to the locations where artists distribute their social content. As more artists from outside of North America become impactful artists on the Billboard charts, additional social platforms should be studied, especially those from Asia.

The top artists in music do not need to rely on social media as much as developing artists because of their visibility headlining top tours and their mentions in press headlines. This type of study for emerging artists would provide an additional lens for artists that do not benefit from an already established fan base. This study did not evaluate the effectiveness of each post, only the frequency by which artists are posting. This engagement is an important aspect to add to future work because more content does not imply the content is better at reaching fans.

\section{References}

Morris, Jeremy Wade. 2014. "Artists as Entrepreneurs, Fans as Workers." Popular Music and Society 37, no. 3: 273-290. https://doi.org/10.1080/03007766.2013.77 $\underline{8534}$.

Shay, Ronen, and Morgan Van Der Horst. 2019. "Using Brand Equity to Model ROI for Social Media Marketing." International Journal on Media Management 21, no. 1: 24-44. https://doi.org/10.1080/14241277.2019.1 590838.

“Top Artists - 2018 Year-End.” Billboard. Accessed March 1, 2019. https://www.billboard.com/charts/yearend/2018/top-artists.

Whiting, Anita, and David Williams. 2013. "Why People Use Social Media: A Uses and Gratifications Approach." Qualitative Market Research: An International Journal 16, no. 4: 362-369. https://doi.org/10.1108/ QMR-06-2013-0041. 


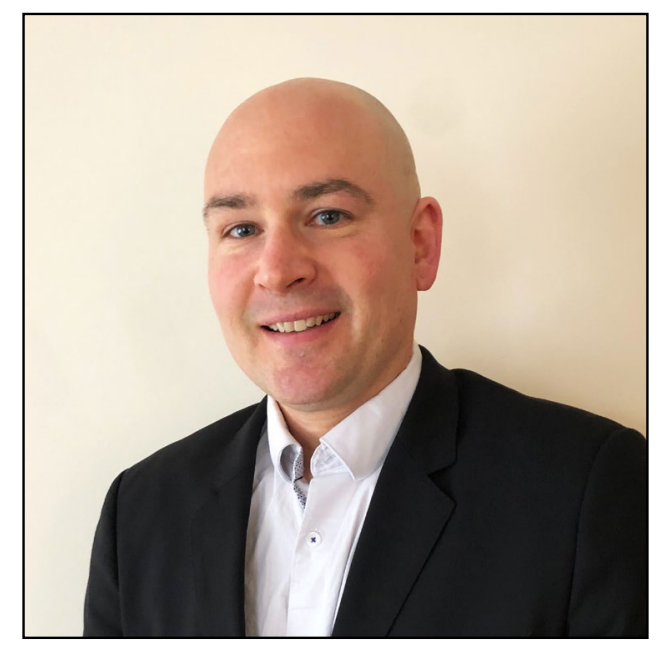

Ulf Oesterle is an Assistant Professor within The Bandier Program at Syracuse University. He has spent the last fifteen years teaching classes focused on the music business, television, radio, and film industries and social media/emerging technology for Syracuse University. Dr. Oesterle currently teaches in the S.I. Newhouse School of Public Communications after nearly a decade within the College of Visual and Performing Arts at Syracuse. As the first full-time faculty hire of The Bandier Program, Oesterle spent significant time on curriculum development, assisted with the launch of the Syracuse University semester in Los Angeles (SULA) and is the former chair of the Music and Entertainment Industries Department. Oesterle also spent a year as the Interim Director for The Bandier Program and Interim Director for the Audio Arts Master's program. Dr. Oesterle is an educator and practitioner, having spent time operating a small record label and artist management company while teaching. For two years he programmed and hosted a commercial specialty radio program on KRock (WKRL) Syracuse. Currently Oesterle is the faculty advisor to the free format college radio station (WERW), advisor to the music and lifestyle campus magazine 20 Watts and contributes to the campus music television program Loud \& Clear. Dr. Oesterle has extensive speaking experience with solo or panel presentations at SXSW, SXSW EDU, The Music and Entertainment Industry Educators Association (MEIEA) Summit, Launch Music Conference, Vegas Music Summit, CMJ, and University of New Mexico Mentoring Institute, among others. 


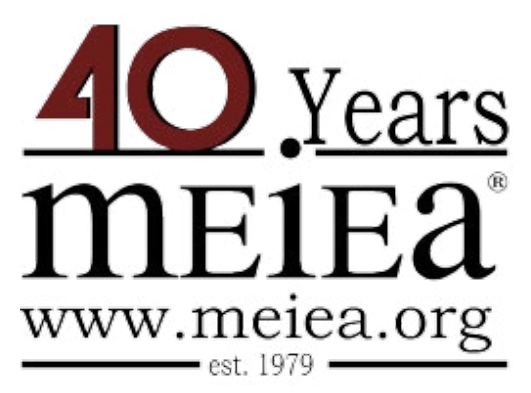

\section{PROCEEDINGS OF THE \\ 2019 INTERNATIONAL SUMMIT \\ OF THE \\ MUSIC \& ENTERTAINMENT \\ INDUSTRY EDUCATORS \\ ASSOCIATION}

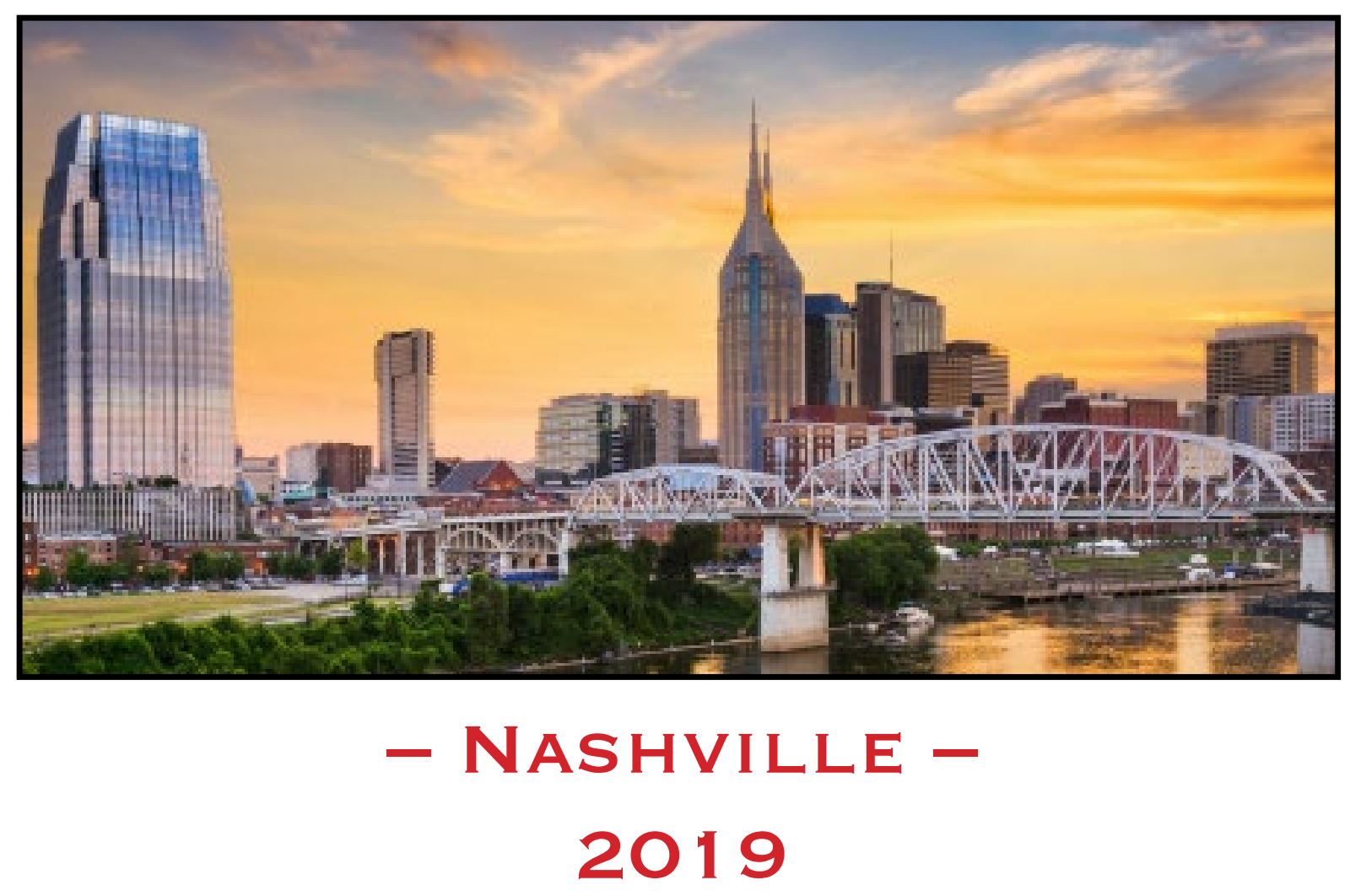

March 21 - 23, $2019 \cdot$ Belmont University - Nashville 